\title{
Impact of chronic airflow obstruction in a working population
}

\author{
N. Roche*,\#, F. Dalmay ${ }^{\uparrow}$, T. Perez ${ }^{+}$, C. Kuntz ${ }^{\S}$, A. Vergnenègre $^{\uparrow}$, F. Neukirch ${ }^{\dagger}$, \\ J-P. Giordanella** and G. Huchon*,\#
}

ABSTRACT: Data on the individual and collective impact of chronic airflow obstruction at a population level are scarce. In a nationwide survey, dyspnoea, quality of life and missed working days were compared between subjects with and without spirometrically diagnosed chronic airflow obstruction.

Subjects aged $\geqslant 45$ yrs were recruited in French health prevention centres $(n=5,008)$. Results of pre-bronchodilator spirometry and questionnaires (European Community Respiratory Health Survey-derived questionnaire and European quality of life five-dimension questionnaire) were collected. Adequate datasets were available for 4,764 subjects aged $60 \pm 10$ yrs (only $2 \%$ were aged $\geqslant 80$ yrs).

The prevalence of airflow obstruction (forced expiratory volume in one second/forced vital capacity of $<\mathbf{0 . 7 0}$ ) was $7.5 \%$. The vast majority $(93.9 \%)$ of cases had not been diagnosed previously. Health status was significantly influenced by dyspnoea. Both were associated with the number of missed working days. Despite mild-to-moderate severity, subjects with chronic airflow obstruction exhibited more dyspnoea, poorer quality of life and higher numbers of missed working days (mean 6.71 versus 1.45 days $\cdot$ patient ${ }^{-1} \cdot \mathrm{yr}^{-1}$ in patients without airflow obstruction, for the population with no known heart or lung disease).

In conclusion, even mild-to-moderate airflow obstruction is associated with an impaired health status, which represents an additional argument in favour of early detection in chronic obstructive pulmonary disease.

KEYWORDS: Chronic obstructive pulmonary disease, dyspnoea, prevalence, quality of life, work loss

hronic obstructive pulmonary disease (COPD) is one of the leading causes of mortality, handicap and healthcare costs worldwide [1, 2]. Its prevalence is high, ranging 4-10\% [3], but the disease remains largely underdiagnosed [4-6]. This may relate to the relatively late occurrence and underestimation of symptoms [7], which correlate poorly with lung function [8].

COPD alters quality of life, mainly through dyspnoea and exacerbations, and is associated with several extrarespiratory manifestations [9, 10]. Ultimately, it leads to respiratory failure and premature death. Based on these assumptions, guidelines advocate the need for early detection of the disease in order to: 1) motivate patients towards smoking cessation [11]; and 2) permit the use of treatments that can reduce the impact of COPD on symptoms, activities, quality of life and healthcare costs $[1,2,12,13]$. However, this impact has seldom been evaluated at the general population level; in most cases, subjects recruited into quality-of-life studies have been patients with known COPD, which excludes the most prevalent fraction of the diseased population, i.e. the less severe and undiagnosed cases. Thus it is difficult to estimate the global consequences of the disease on health status in the population, and the possible effect of early detection at this level.

The present analysis was designed to assess the impact of chronic airflow obstruction on dyspnoea, quality of life (measured with a generic questionnaire) and missed working days in a population sample that was constituted with the primary objective of determining the prevalence of chronic airflow obstruction [14].

\section{MATERIALS AND METHODS}

\section{Study design}

Subjects were recruited in 31 health prevention centres that are accessible to all workers. The sample was constructed according to national statistics on age and sex distribution in the

\section{AFFILIATIONS}

*René Descartes University of Paris,

Respiratory and Intensive Care

Medicine, Hôtel-Dieu Hospital,

${ }^{\text {\#}}$ National Committee against

Respiratory Diseases,

${ }^{f}$ INSERM U700, Xavier Bichat

Medical University,

${ }^{* \star}$ Caisse Nationale d'Assurance

Maladie, Paris,

-University of Limoges, UF Clinical

Research and Biostatistics, Limoges,

+University of Lille, Respiratory

Medicine, Calmette Hospital, Lille,

and

${ }^{\S}$ Technical Support and Formation

Centre, Saint-Étienne, France.

CORRESPONDENCE

N. Roche, Service de Pneumologie et

Réanimation, Hôtel-Dieu de Paris, 1

Parvis Notre Dame, F-75181 Paris

04, France. Fax: 33142348448

E-mail: nicolas.roche@htd.aphp.fr

Received:

July 162007

Accepted after revision:

January 062008

\section{SUPPORT STATEMENT}

This work was promoted by the National Committee against Respiratory Diseases (Paris, France) and the Technical Support and Formation Centre (Saint-Étienne, France), and supported by a grant from the Association for the Study of Respiration and Environment (Paris, France).

STATEMENT OF INTEREST A statement of interest for N. Roche, $T$. Perez, $A$. Vergnenègre and G. Huchon, and the study itself can be found at www.erj.ersjournals.com/ misc/statements.shtml 
general population of the considered age range (subjects aged $\geqslant 40$ yrs). Subjects filled in a standardised auto-questionnaire, and a technician who was not aware of the answers to the questionnaire measured forced expiratory volume in one second (FEV1) and forced vital capacity (FVC). All subjects received an information note before their participation.

\section{Questionnaire and spirometry}

The data obtained from each individual included the usual demographic and anthropometric description, information on risk factors, clinical symptoms, associated chronic diseases and presumptive diagnosis, and previous assessment of lung function.

The questionnaire was derived from the European Community Respiratory Health Survey questionnaire [15]. Details of its content have already been published. Dyspnoea was measured using the modified UK Medical Research Council 0-4 scale, and quality of life was assessed using a generic five-dimension questionnaire, the European quality of life five-dimension (EuroQol-5D/EQ-5D) questionnaire [16]. Declared missed working days during the previous year were recorded.

Pre-bronchodilator spirometry was performed by trained technicians using spirometers that were calibrated daily. Three measures were performed, with the best technically adequate measurement being chosen for analysis. Subjects were excluded from the analyses when only one spirometric measurement was adequate or when the variation between the two highest FEV1 was $>200 \mathrm{~mL}$. Predicted values were calculated using European Respiratory Society equations [17, 18]. Airflow obstruction was defined by an FEV1/FVC ratio of $<0.70$.

\section{Statistical analysis}

The present study was powered to assess the prevalence of chronic airflow obstruction in the chosen population. Considering the expected prevalence of airflow obstruction of $\sim 5 \%$, an allowed risk of error of $0.5 \%$ of this percentage and possible analysis in two strata, 4,500 individuals had to be recruited for the present survey. Results are expressed as percentages or mean $\pm \mathrm{SD}$.

Based on questionnaire data, analyses were performed in three populations: the whole population, nonasthmatics, and subjects with no declared respiratory or cardiac disease.

In each of these populations, percentages were compared by two-way and multi-way frequency analysis, and means by ANOVA and unpaired t-tests. Relationships between continuous variables were assessed using linear regression. A difference was considered significant at a $p$-value of $<0.05$. Bonferroni corrections were performed for multiple comparisons.

Finally, multivariate logistic regression analyses were performed in order to identify independent predictors of quality of life and work loss. For these analyses, the dependent variables were: 1) the scores of each EQ-5D domain, and 2) the presence or absence of $\geqslant 1$ missed working day, respectively. This last analysis was restricted to the active fraction of the population, i.e. subjects aged $<65$ yrs.

\section{RESULTS}

\section{Characteristics of the studied population}

A total of 5,008 subjects were included in the present survey during an 8-month recruitment period; this corresponded to a $93.5 \%$ response rate among subjects initially asked to participate. Adequate questionnaire and spirometry data were available for $4,764(95.1 \%)$ subjects (table 1$)$. Their mean age was $60 \mathrm{yrs} ; 81 \%$ of subjects were aged $<70$ yrs and only $2 \%$ were aged $>80$ yrs. Known chronic respiratory disease was reported by $9.1 \%$ of subjects for asthma, $2.6 \%$ for COPD and $5.8 \%$ for chronic bronchitis. Questions regarding symptoms revealed that chronic bronchitis was genuinely present in 3.9\% of subjects. The prevalence of chronic airflow obstruction in nonasthmatics was $7.5 \%$. In the majority (59\%) of these patients, the severity of airflow obstruction was mild (FEV1 of $\geqslant 80 \%$ of the predicted value) and chronic bronchitis was absent. The severity of airflow obstruction was moderate (FEV1 of $50-80 \%$ pred) in $36.1 \%$, and severe or very severe (FEV1 of $<50 \%$ pred) in $4.8 \%$. Among nonasthmatic subjects in whom airflow obstruction was found, only $6.1 \%$ had been previously diagnosed as having a chronic respiratory disease.

\section{Impact of chronic airflow obstruction: dyspnoea and quality of life}

In the whole population and in subjects with no known heart or lung disease, dyspnoea grade correlated significantly $(\mathrm{p}<0.0001)$ but weakly $(\mathrm{r}=0.28)$ with the EQ-5D visual analogue scale score. There were also significant relationships between dyspnoea grade and EQ-5D subscores (mobility, activity, anxiety, autonomy and pain; all $\mathrm{p}<0.001$; data from the whole population are shown in table 2).

Altogether, $7.2 \%$ of subjects with grade 0 dyspnoea showed airflow obstruction versus $10.7 \%$ of those with dyspnoea of grade $\geqslant 1,14.8 \%$ of those with dyspnoea of grade $\geqslant 2$ and $21.8 \%$ of those with grade 4 dyspnoea.

In subjects without known chronic respiratory or heart disease, but who were diagnosed as having airflow obstruction during the examination, the severity of dyspnoea increased with that of airflow obstruction (fig. 1).

In the whole population, patients who declared having asthma, COPD or chronic heart failure exhibited lower aggregated EQ$5 \mathrm{D}$ scores than controls, with all domains of the questionnaire being affected (data not shown). In patients with no chronic respiratory or cardiac disease, EQ-5D visual analogue scale scores decreased with FEV1 (\% pred; mean score $70.5 \pm 14.8$ versus $72.8 \pm 14.8$ in subjects with and without airflow obstruction; $p=0.004$ ), whereas, in all EQ-5D domains, airflow obstruction was associated with lower proportions of patients declaring no limitation than among subjects with no airflow obstruction (87 versus 93\% for mobility, 97 versus 99\% for autonomy, 90 versus $93 \%$ for activity, 38 versus $46 \%$ for pain and 49 versus $55 \%$ for anxiety; all $\mathrm{p}<0.05)$. Multivariate analysis showed that age and FEV1 were independent predictors of all EQ-5D domains except anxiety, which was mainly influenced by sex (table 3 ).

\section{Missed working days}

The number of missed working days was significantly associated with: 1) health status, as measured by EQ-5D visual 
TABLE 1 Description of studied population

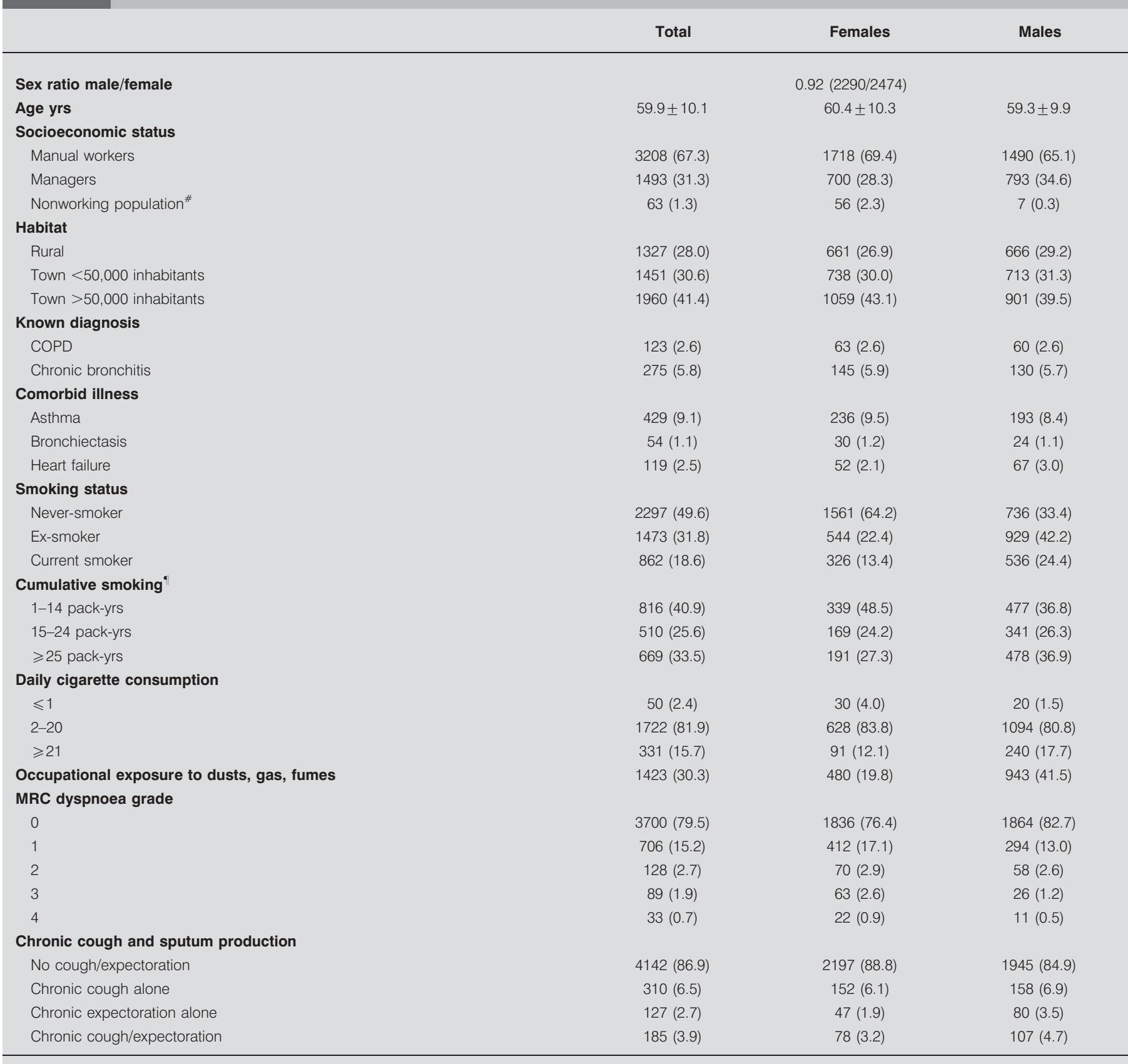

Data are presented as mean \pm SD or $n(\%)$, unless otherwise indicated (percentages given for cumulative smoking are based on total current and ex-smoking population) COPD: chronic obstructive pulmonary disease; MRC: Medical Research Council. "*: retired and others; ": current and ex-smokers.

analogue scale and all EQ-5D domains except autonomy; and 2) dyspnoea grade (data not shown; $\mathrm{p}<0.01$ for all analyses).

Most subjects reported no missed working days during the year preceding the examination (fig. 2). However, in all groups (whole population, nonasthmatics and subjects with no declared respiratory or cardiac disease), a decreased FEV1/ FVC ratio was associated with an increase in the number of missed working days $(6.71 \pm 39.09$ versus $1.45 \pm 14.33$ days in subjects with no respiratory or heart disease; $\mathrm{p}=0.0015)$. In the whole population and in nonasthmatics, the number of missed working days was higher in subjects reporting symptoms of chronic bronchitis than in other subjects $(5.56 \pm 15.45$ versus $1.75 \pm 16.54$ days; $p=0.05$ ), and patients with an FEV1 of 50 $80 \%$ pred missed more working days than those with an FEV1 of $\geqslant 100 \%$ pred $(4.62 \pm 32.80$ versus $1.54 \pm 13.90$ days; $p=0.04)$. These differences were nonsignificant in nonasthmatics declaring no comorbid respiratory or cardiac disease. Other differences between FEV1 categories were also nonsignificant. On multivariate analysis, chronic bronchitis was the only 


\begin{tabular}{llllll} 
TABLE 2 & $\begin{array}{l}\text { Relationship between dyspnoea grade and } \\
\text { generic questionnaire } \\
\text { population/nonasthmatic patients with airflow } \\
\text { obstruction }\end{array}$ \\
\cline { 2 - 6 } $\begin{array}{l}\text { Dyspnoea } \\
\text { grade }\end{array}$ & \multicolumn{5}{c}{ Domain } \\
\cline { 2 - 6 } & Mobility & Autonomy & Activity & Anxiety & Pain \\
\hline & $95.6 / 91.5$ & $99.3 / 98.0$ & $95.7 / 93.1$ & $54.7 / 57.4$ & $50.3 / 45.6$ \\
$\mathbf{0}$ & $86.1 / 82.1$ & $98.3 / 100.0$ & $87.5 / 89.5$ & $36.9 / 29.9$ & $29.6 / 35.8$ \\
$\mathbf{1}$ & $74.2 / 61.1$ & $95.3 / 88.9$ & $79.7 / 77.8$ & $33.9 / 38.9$ & $14.8 / 16.7$ \\
$\mathbf{2}$ & $55.1 / 53.3$ & $90.9 / 86.7$ & $67.1 / 66.7$ & $22.5 / 26.7$ & $17.2 / 26.7$ \\
$\mathbf{3}$ & $54.6 / 40.0$ & $81.8 / 80.0$ & $63.6 / 40.0$ & $30.3 / 20.0$ & $3.0 / 0.0$ \\
$\mathbf{4}$ & & & & & \\
\hline
\end{tabular}

Data are presented as the percentage of the whole population/nonasthmatic patients with aiffow obstruction in each dyspnoea grade who report no limitation/impairment in the domain under consideration. ${ }^{*}$ : European quality of life five-dimension questionnaire.

independent predictor of missed working days (odds ratio 6.0; 95\% confidence interval 2.8-12.7; $\mathrm{p}<0.0001$; table 3 ), but interacted strongly with airflow obstruction $(p<0.001$ in test for interaction).

\section{DISCUSSION}

In the present sample of 4,764 subjects visiting health prevention centres, airflow obstruction was present in $7.5 \%$ of nonasthmatics and was of mild-to-moderate severity in the vast majority of cases. In these subjects, exertional dyspnoea was more frequent, quality of life assessed by the EQ-5D generic questionnaire was poorer and the number of missed working days was greater than in other subjects. The vast majority (93.9\%) of subjects with airflow obstruction were not previously known to be suffering from any kind of chronic respiratory disease.

\section{Limitations and strengths of the study}

To the best of the present authors' knowledge, the present study is one of the largest spirometrically based population studies assessing the impact of chronic airflow obstruction using a validated quality-of-life questionnaire.

Airflow obstruction was defined according to pre-bronchodilator spirometry results, which is not in accordance with current guidelines. However, this was inevitable since French health prevention centres are not permitted to deliver any kind of medication. In addition, the use of pre-bronchodilator results is in line with several recent epidemiological studies, such as those of DE MARCO and co-workers [15, 19]. In their most recent article, these authors conclude that the use of prebronchodilator values results in exposure to a risk of overestimation of the prevalence of COPD. They also show that this risk is minimised by exclusion of asthmatic subjects. For this reason, all analyses were performed in the whole population, in nonasthmatics alone and in subjects with no known heart or respiratory disease. Regarding FEV1/FVC ratio, the use of the fixed 0.70 cut-off rather than the lower limit of normal for the diagnosis of airflow obstruction may result in overestimation of the prevalence of the disease in the elderly

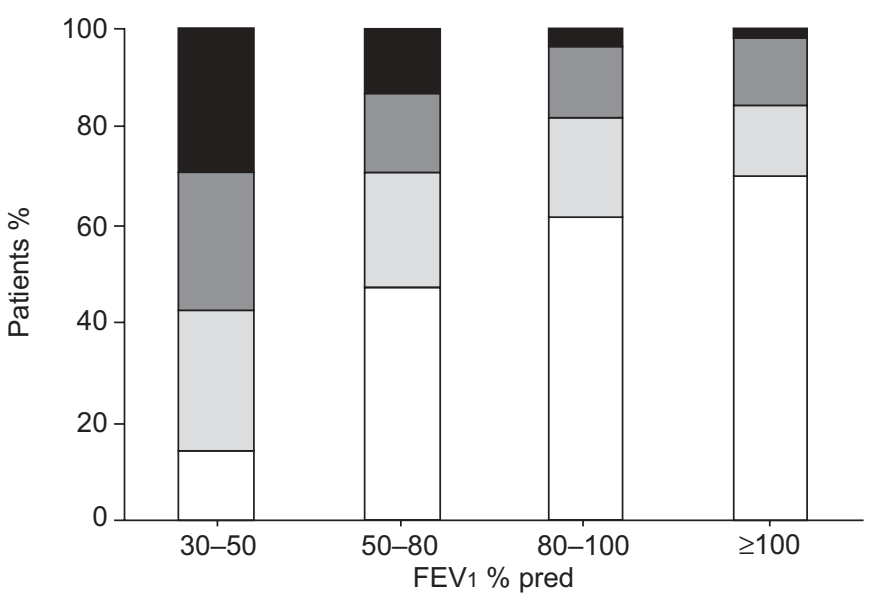

FIGURE 1. UK Medical Research Council dyspnoea grades ( $\square: 0 ; \square: 1 ; \square: 2$; 口: 3) by forced expiratory volume in one second (FEV1) in subjects with no known heart or lung disease but in whom chronic airflow obstruction (FEV $1 /$ forced vital $^{2}$ capacity of $<0.70$ ) was demonstrated. No subjects reported grade 4 dyspnoea. $\%$ pred: \% predicted.

(and underestimation in younger adults, although the latter did not form part of the present study population). However, for practical reasons, the fixed cut-off is the recommended means of diagnosing chronic airflow obstruction in current guidelines. In addition, elderly subjects and those aged $<40$ yrs represented a small part of the present population, limiting the overall risk of error.

The mode of recruitment was certainly a source of bias since: 1) the main purpose of health examination centres is prevention; and 2) visits to these centres are offered mainly to the working population. Thus subjects of the studied population are less likely to exhibit symptoms or be known to have any disease than the general population (healthy worker effect). Accordingly, the proportion $(6.1 \%)$ of patients with a known diagnosis of COPD was lower than in other studies $[4,5,20]$. Thus the prevalence and impact of chronic airflow obstruction may be underestimated, which may help to explain the low number of subjects with an FEV1 of $<50 \%$ pred and the low proportion of subjects with airflow obstruction who reported symptoms of chronic bronchitis, severe dyspnoea or a previously known diagnosis of respiratory disease. In addition, the results presented herein cannot be extrapolated to the nonworking population. Despite these considerations, the overall prevalence data were very similar to those from other studies in developed countries regarding asthma, chronic bronchitis and airflow obstruction [4, 5, 21-23].

Another limitation is the declarative nature of the data on work loss. There is no means of assessing how this may have affected the present results. It can only be assumed that, since missed working days are important events in the life of workers, they are likely to be remembered accurately enough and not significantly overestimated.

\section{Impact of airflow obstruction}

Despite its mild severity, patients with chronic airflow obstruction exhibited poorer quality of life and increased dyspnoea and number of missed working days. 


\begin{tabular}{|c|c|c|c|}
\hline $\begin{array}{l}\text { Predic } \\
\text { days c } \\
\text { in sub }\end{array}$ & $\begin{array}{l}\text { of quality } \\
\text { ultivariate I } \\
\text { without a }\end{array}$ & $\begin{array}{l}\text { life and miss } \\
\text { gistic regress } \\
\text { nown diagno }\end{array}$ & $\begin{array}{l}\text { working } \\
\text { analysis }\end{array}$ \\
\hline EQ-5D domain & Reference & OR $(95 \% \mathrm{Cl})$ & $\mathrm{p}$-value \\
\hline Mobility 2 & 1 & & \\
\hline FEV $130-<50 \%$ pred & $\geqslant 80 \%$ pred & $13.8(2.6-73.9)$ & 0.0022 \\
\hline FEV $150-<80 \%$ pred & $\geqslant 80 \%$ pred & $1.8(1.1-3.0)$ & 0.0208 \\
\hline Age $\geqslant 75$ yrs & $45-54$ yrs & $3.1(1.0-9.4)$ & 0.0428 \\
\hline Activity 2 & 1 & & \\
\hline FEV $150-<80 \%$ pred & $\geqslant 80 \%$ pred & $2.0(1.2-3.4)$ & 0.0062 \\
\hline Age $\geqslant 75$ yrs & $45-54$ yrs & $5.0(1.5-16.6)$ & 0.0089 \\
\hline Daily cigarettes $\geqslant 21$ & 2-20 & $2.1(1.1-3.9)$ & 0.0198 \\
\hline Anxiety 2 & 1 & & \\
\hline Female sex & Male & $2.1(1.7-2.7)$ & $<0.0001$ \\
\hline Anxiety 3 & 1 & & \\
\hline Female sex & Male & $3.7(2.3-6.0)$ & $<0.0001$ \\
\hline Pain 2 & 1 & & \\
\hline FEV1 $50-<80 \%$ pred & $\geqslant 80 \%$ pred & $1.4(1.1-1.9)$ & 0.0190 \\
\hline Age $\geqslant 75$ yrs & $45-54$ yrs & $1.9(1.1-3.4)$ & 0.0325 \\
\hline Pain 3 & 1 & & \\
\hline Age 55-64 yrs & $45-54$ yrs & $3.0(1.4-6.4)$ & 0.0048 \\
\hline Age $65-74$ yrs & $45-54$ yrs & $3.6(1.0-12.2)$ & 0.0432 \\
\hline Age $\geqslant 75$ yrs & $45-54$ yrs & $4.4(1.1-18.4)$ & 0.0414 \\
\hline FEV1 $50-<80 \%$ pred & $\geqslant 80 \%$ pred & $2.1(1.1-4.0)$ & 0.0212 \\
\hline \multicolumn{4}{|c|}{ Missed working day $\geqslant 1^{+}$} \\
\hline Chronic bronchitis & None & $6.0(2.8-12.7)$ & $<0.0001$ \\
\hline \multicolumn{4}{|c|}{$\begin{array}{l}\text { EQ-5D: European quality of life five-dimension questionnaire; OR: odds ratio; } \\
\mathrm{Cl} \text { : confidence interval; FEV1: forced expiratory volume in one second; \% pred: } \\
\% \text { predicted. }{ }^{*} \text { : of chronic obstructive pulmonary disease, asthma or any other } \\
\text { predefined comorbid illness (bronchiectasis or chronic heart failure); }{ }^{\circ} \text { no } \\
\text { independent predictor was found for mobility class } 3 \text { or activity class } 3 ;{ }^{+} \text {: } \\
\text { analysis restricted to those aged }<65 \text { yrs }(n=1,310) .\end{array}$} \\
\hline
\end{tabular}

This observation remained true even in patients with no known heart or lung illness.

\section{Dyspnoea}

In the present patients, impairment of quality of life was influenced by dyspnoea, although this symptom was much less severe than in patients with possible COPD identified in the Confronting COPD survey [6]. For instance, among persistent smokers with a Global Initiative for Chronic Obstructive Lung Disease airflow obstruction stage of $>1$ (in whom dyspnoea was the most prevalent), only $8.3 \%$ reported a dyspnoea grade of $\geqslant 3$, whereas the corresponding figure in the Confronting COPD survey was $42.6 \%$. Thus even mild dyspnoea can be associated with impaired quality of life.

\section{Quality of life}

Among subjects with chronic airflow obstruction identified in the general population, a diagnosis of COPD is more likely when quality of life is more impaired [24]. In addition, lung function is an independent predictor of all EQ-5D domains except anxiety. However, despite the under-representation of severe cases and marked underdiagnosis of COPD in the present study, quality of life was impaired by airflow
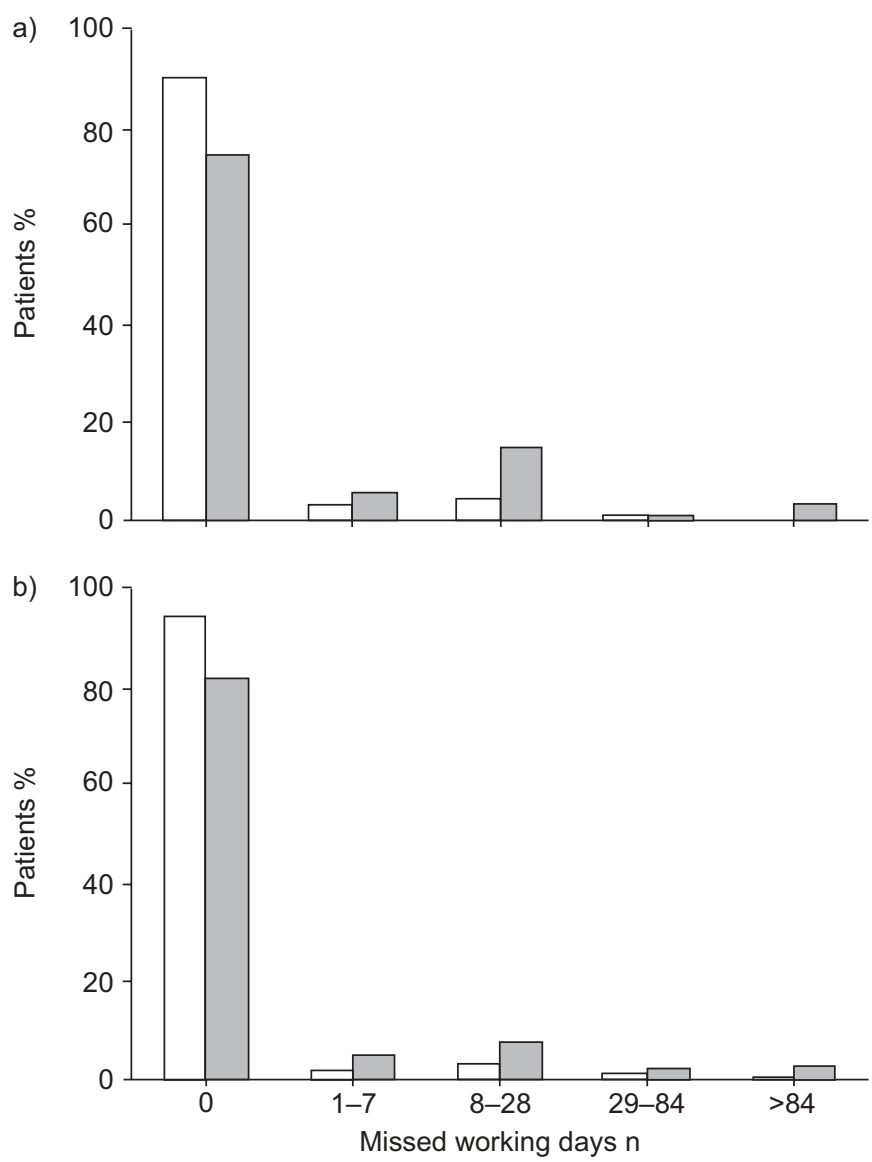

FIGURE 2. Distribution of number of missed working days reported during the previous year in the population with no known lung or heart disease, by presence $(\square)$ or absence $(\square)$ of a) chronic bronchitis and b) airflow obstruction.

obstruction. In the USA, the National Health and Nutrition Examination Survey (NHANES) also showed that undiagnosed airflow obstruction in the general population is associated with impaired health and functional status. In that study, health status was not assessed using a dedicated questionnaire but rather with questions about general health status, walking $402 \mathrm{~m}$, lifting or carrying something as heavy as $4.54 \mathrm{~kg}$ and needing help with personal care [25]. In the Confronting COPD survey [6], patients with airflow obstruction also reported activity restrictions related to their respiratory condition. Depending upon the item under consideration, $30-70 \%$ of subjects with or at risk of COPD reported limitations in sport and recreation, physical exertion, social life, sleep, household chores and sex life. In line with these findings, data from the Spanish EPIDEPOC study found significant impairment of quality of life measured with the 12-item short-form health survey questionnaire in stable COPD subjects followed in primary care, even in mild disease stages [26].

\section{Impact on work}

COPD is not only a disease of the elderly; its prevalence in subjects aged $\leqslant 65$ yrs is not negligible and has a noticeable impact on resource utilisation and healthcare costs [27]. In these subjects, ability to work is an important determinant of life satisfaction [28]. In the Confronting COPD survey [6], 
$35.7 \%$ of patients reported that "their condition prevented them from working, limited their ability to work or had caused them working time loss in the past year". This percentage increased to 45.3 in subjects aged $<65$ yrs, who were less likely to form part of the $54.8 \%$ of the population who were retired [7]. The proportion of retired subjects was much lower $(1.3 \%)$ in the present population; this is related to the mode of recruitment since health examination centres target only working subjects. The much lower proportion of subjects reporting work loss in the present population is probably related to several factors: slightly younger age (60 versus 63 yrs in the Confronting COPD survey [6]), different mode of recruitment (systematic prevention visits by subjects who presume they are healthy versus general population) and variable studied; the present study used only the number of missed working days to assess disease consequences on work, whereas RENNARD et al. [7] also included reported "limitations in the ability to work" in their assessment, introducing a possibly more subjective component, the contribution of which it is difficult to assess. Finally, there was no means of determining whether or not airflow obstruction was less severe in the present population than in the Confronting COPD survey [6], since lung function was not assessed in that study.

In NHANES III, even patients with spirometrically mild COPD were less likely to be in the labour force than controls. More precisely, mild, moderate and severe COPD were associated with a $3.4,3.9$ and $14.4 \%$ reduction in the labour force participation rate relative to those without COPD [29].

Finally, multivariate analysis did not identify lung function as an independent predictor of missed working days, whereas chronic bronchitis was so identified. Thus, when the COPD fraction of a population has mostly mild or mild-to-moderate disease, work loss seems to relate more to chronic bronchitis than to airflow obstruction. However, this result should be interpreted with caution since the power of the analysis was relatively low, due to the small number of subjects reporting any missed working day $(n=69)$ among the population restricted to those aged $<65$ yrs with no cardiac or respiratory comorbid illness $(n=1,310)$. This also prevented reliable multivariate analysis with the number of missed working days divided into subcategories.

In conclusion, the present study on a large sample from health prevention centres found a significant impact of mild-tomoderate airflow obstruction on dyspnoea, quality of life and missed working days despite a very low proportion of subjects spontaneously reporting symptoms or a known respiratory disease. Such findings suggest that systematic screening for chronic obstructive pulmonary disease may be justified in the general population since identified cases suffer from a significant although underestimated impact of the disease, which might be limited by early implementation of preventive and therapeutic measures.

\section{ACKNOWLEDGEMENTS}

The authors would like to thank M-F. Doré, B. Mansour (HótelDieu, Paris France) and N. Le Corre (E-ness, Aix en Provence, France) for their help in lung function test training, C. Petit (Boehringer Ingelheim, Reims, France) for the initial statistical analysis and all of the following health prevention centres in France for their involvement: Amiens, Belfort, Caen, Cenon, Chartres, Dijon, Douai, Dunkirk, La Roche-sur-Yon, Le Havre, Lille, Limoges, Lyon, Marseille, Mulhouse, Nice, Nîmes, Orléans, Paris, Pau, Poitiers, Reims, Rennes, Saint-Brieuc, Saint-Étienne, Saint-Nazaire, Tarbes, Toulouse, Vandoeuvrelès-Nancy, and Vesoul.

\section{REFERENCES}

1 Celli BR, MacNee W. Standards for the diagnosis and treatment of patients with COPD: a summary of the ATS/ ERS position paper. Eur Respir J 2004; 23: 932-946.

2 Pauwels RA, Buist AS, Calverley PM, Jenkins CR, Hurd SS, on behalf of the GOLD Scientific Committee. Global strategy for the diagnosis, management, and prevention of chronic obstructive pulmonary disease. NHLBI/WHO Global Initiative for Chronic Obstructive Lung Disease (GOLD) Workshop summary. Am J Respir Crit Care Med 2001; 163: 1256-1276.

3 Halbert RJ, Isonaka S, George D, Iqbal A. Interpreting COPD prevalence estimates: what is the true burden of disease? Chest 2003; 123: 1684-1692.

4 Mannino DM, Gagnon RC, Petty TL, Lydick E. Obstructive lung disease and low lung function in adults in the United States: data from the National Health and Nutrition Examination Survey, 1988-1994. Arch Intern Med 2000; 160: 1683-1689.

5 Pena VS, Miravitlles M, Gabriel R, et al. Geographic variations in prevalence and underdiagnosis of COPD: results of the IBERPOC multicentre epidemiological study. Chest 2000; 118: 981-989.

6 Halbert R, Natoli J, Gano A, Tinkelman D. Prevalence of undiagnosed COPD: systematic review and meta-analysis. Eur Respir J 2007; 30: Suppl. 51, 34s.

7 Rennard S, Decramer M, Calverley PM, et al. Impact of COPD in North America and Europe in 2000: subjects' perspective of Confronting COPD International Survey. Eur Respir J 2002; 20: 799-805.

8 Mahler DA, Harver A. A factor analysis of dyspnea ratings, respiratory muscle strength, and lung function in patients with chronic obstructive pulmonary disease. Am Rev Respir Dis 1992; 145: 467-470.

9 Jones PW, Kaplan RM. Methodological issues in evaluating measures of health as outcomes for COPD. Eur Respir J 2003; 21: Suppl. 41, 13s-18s.

10 Jones PW, Agusti AG. Outcomes and markers in the assessment of chronic obstructive pulmonary disease. Eur Respir J 2006; 27: 822-832.

11 Gorecka D, Bednarek M, Nowinski A, Puscinska E, GoljanGeremek A, Zielinski J. Diagnosis of airflow limitation combined with smoking cessation advice increases stopsmoking rate. Chest 2003; 123: 1916-1923.

12 Société de Pneumologie de Langue Française. [Frenchlanguage Society of Pneumology.] Recommandations pour la prise en charge de la bronchopneumopathie chronique obstructive. [Guidelines on chronic obstructive pulmonary disease.] Rev Mal Respir 2003; 20: 294-329.

13 Halpin D. NICE guidance for COPD. Thorax 2004; 59: 181-182. 
14 Roche N, Dalmay F, Perez $\mathrm{T}$, et al. Variation in the prevalence of chronic airflow obstruction with the definition used. Proc Am Thorac Soc 2006; 3: A616.

15 de Marco R, Accordini S, Cerveri I, et al. An international survey of chronic obstructive pulmonary disease in young adults according to GOLD stages. Thorax 2004; 59: 120-125.

16 Rutten-van Molken MP, Oostenbrink JB, Tashkin DP, Burkhart D, Monz BU. Does quality of life of COPD patients as measured by the generic EuroQol five-dimension questionnaire differentiate between COPD severity stages? Chest 2006; 130: 1117-1128.

17 Quanjer PH, Tammeling GJ, Cotes JE, Pedersen OF, Peslin R, Yernault JC. Lung volumes and forced ventilatory flows. Report Working Party Standardization of Lung Function Tests, European Community for Steel and Coal. Official Statement of the European Respiratory Society. Eur Respir J 1993; 6: Suppl. 16, S5-S40.

18 Quanjer PH, Lebowitz MD, Gregg I, Miller MR, Pedersen OF. Peak expiratory flow: conclusions and recommendations of a Working Party of the European Respiratory Society. Eur Respir J 1997; 10: Suppl. 24, 2S-8S.

19 de Marco R, Accordini S, Cerveri I, et al. Incidence of chronic obstructive pulmonary disease in a cohort of young adults according to the presence of chronic cough and phlegm. Am J Respir Crit Care Med 2007; 175: 32-39.

20 Wouters EF. Economic analysis of the Confronting COPD survey: an overview of results. Respir Med 2003; 97: Suppl. C, S3-S14.

21 Viegi G, Pedreschi M, Pistelli F, et al. Prevalence of airways obstruction in a general population: European Respiratory
Society us American Thoracic Society definition. Chest 2000; 117: Suppl. 2, 339S-345S.

22 Zielinski J, Bednarek M. Early detection of COPD in a highrisk population using spirometric screening. Chest 2001; 119: 731-736.

23 Halbert RJ, Natoli JL, Gano A, Badamgarav E, Buist AS, Mannino DM. Global burden of COPD: systematic review and meta-analysis. Eur Respir J 2006; 28: 523-532.

24 Miravitlles M, Ferrer M, Pont A, et al. Characteristics of a population of COPD patients identified from a populationbased study. Focus on previous diagnosis and never smokers. Respir Med 2005; 99: 985-995.

25 Coultas DB, Mapel D, Gagnon R, Lydick E. The health impact of undiagnosed airflow obstruction in a national sample of United States adults. Am J Respir Crit Care Med 2001; 164: 372-377.

26 Carrasco Garrido P, de Miguel Díez J, Rejas Gutiérrez J, et al. Negative impact of chronic obstructive pulmonary disease on the health-related quality of life of patients. Results of the EPIDEPOC study. Health Qual Life Outcomes 2006; 4: 31.

27 Tinkelman DG, George D, Halbert RJ. Chronic obstructive pulmonary disease in patients under age 65: utilization and costs from a managed care sample. J Occup Environ Med 2005; 47: 1125-1130.

28 Sturesson M, Inga-Britt B. Life satisfaction in subjects with chronic obstructive pulmonary disease. Work 2000; 14: 77-82.

29 Sin DD, Stafinski T, Ng YC, Bell NR, Jacobs P. The impact of chronic obstructive pulmonary disease on work loss in the United States. Am J Respir Crit Care Med 2002; 165: 704-707. 